OPEN ACCESS

Edited by:

Yanhui Liao,

Sir Run Run Shaw Hospital, China

Reviewed by:

Yu-Tao Xiang,

University of Macau, China

Bao-Liang Zhong,

China University of Geosciences

Wuhan, China

Ruiling Zhang,

Second Affiliated Hospital of Xin Jiang Medical University, China

${ }^{*}$ Correspondence: Hongxian Shen shenhx2018@csu.edu.cn

tThese authors have contributed equally to this work and share first

authorship

Specialty section:

This article was submitted to

Addictive Disorders,

a section of the journal

Frontiers in Psychiatry

Received: 25 August 2020 Accepted: 22 October 2020 Published: 17 November 2020

Citation:

Liao Z, Huang Q, Huang S, Tan L, Shao T, Fang T, Chen X, Lin S, Qi J, Cai Y and Shen H (2020) Prevalence of Internet Gaming Disorder and Its Association With Personality Traits and Gaming Characteristics Among Chinese Adolescent Gamers.

Front. Psychiatry 11:598585.

doi: 10.3389/fpsyt.2020.598585

\section{Prevalence of Internet Gaming Disorder and Its Association With Personality Traits and Gaming Characteristics Among Chinese Adolescent Gamers}

\author{
Zhenjiang Liao ${ }^{1,2 t}$, Qiuping Huang ${ }^{1,2 t}$, Shucai Huang ${ }^{3}$, Linxiang Tan ${ }^{4}$, Tianli Shao ${ }^{1,2}$, \\ Ting Fang ${ }^{1,2}$, Xinxin Chen ${ }^{1,2}$, Shuhong Lin ${ }^{1,2}$, Jing Qi ${ }^{5}$, Yi Cai ${ }^{6}$ and Hongxian Shen ${ }^{1,2 \star}$ \\ ${ }^{1}$ National Clinical Research Center for Mental Disorders, Department of Psychiatry, The Second Xiangya Hospital of Central \\ South University, Changsha, China, ${ }^{2}$ Hunan Key Laboratory of Psychiatry and Mental Health, Hunan Medical Center for \\ Mental Health, Chinese National Technology Institute on Mental Disorders, Institute of Mental Health of Central South \\ University, Changsha, China, ${ }^{3}$ Department of Psychiatry, The Fourth People's Hospital of Wuhu, Wuhu, China, ${ }^{4}$ Education \\ Center for Mental Health, Central South University, Changsha, China, ${ }^{5}$ Department of Psychiatry, Brain Hospital of Hunan \\ Province, Changsha, China, ${ }^{6}$ Department of Psychiatry, Comorbid Somatic Diseases, Shenzhen Kangning Hospital, \\ Shenzhen, China
}

Background: Internet gaming is extremely popular in China. However, some players overuse it, with negative outcomes. Knowing the prevalence rate and specific risk factors can provide a better understanding of the etiology of Internet Gaming Disorder (IGD). This study aimed to estimate the prevalence of IGD among Chinese adolescents and its association with their personality traits and Internet gaming characteristics.

Methods: A cross-sectional study design was utilized in this study. Participants were recruited from 34 provincial administrative districts in China and consisted of 6,379 adolescent game players aged 15-25 (males/females $=3,701 / 2,678$, mean age: $19.35 \pm 1.61)$. A self-report structured questionnaire containing questions regarding demographic information and Internet gaming use characteristics, the Video Gaming Dependency Scale, and the Chinese Big Five Inventory-brief version, was used in the study.

Results: The prevalence of IGD among Chinese adolescent game players was $17.0 \%$. All participants were divided into the IGD group (males/females $=751 / 333$, mean age: $19.74 \pm 1.85$ ) or the non-IGD group (males/females $=2,950 / 2,345$, mean age: 19.27 \pm 1.54). Specifically, twelve factors were significantly associated with IGD $(p<0.001)$, including neuroticism $(\beta=0.17)$, conscientiousness $(\beta=-0.14)$, Internet gaming time per day (Hour) $(\beta=0.21)$, Internet gaming charge per month (Yuan) $(\beta=0.21)$, motive: escaping $(\beta=0.15)$, motive: sensation seeking $(\beta=0.13)$, motive: maintaining ( $\beta=0.08)$, motive: coping $(\beta=0.06)$, having one or two long-term game partners $(\beta=0.06)$, male $(\beta=0.12)$, undergraduate and above $(\beta=0.04)$, and relationship status of couple $(\beta=0.04)$. 


\begin{abstract}
Conclusion: Our findings offer evidence with respect to the prevalence of IGD and its relationships with specific personality traits and Internet gaming characteristics in China. It is necessary for Chinese parents, teachers, and social workers to pay more attention to adolescents' personality traits of high neuroticism and low conscientiousness, long time and high expense they spend on game, as well as their motives.
\end{abstract}

Keywords: internet gaming disorder (IGD), internet gaming use characteristics, personality traits (big five), big five model, Chinese adolescent gamers

\section{INTRODUCTION}

Given the characteristics of Internet games (free access, unlimited use, strong interactivity, and instant rewards), immersion in Internet gaming has become increasingly common and an important part of daily activities for adolescents and adults (1). As of June 2019, there were 494 million Internet game users in China, accounting for $57.8 \%$ of all Internet users (854 million) (2). Most people play games healthily, which can provide benefits for users (3). However, some players show overuse and symptoms similar to those of substance addictions (4), which may result in negative outcomes such as depression, anxiety, academic dysfunction, poor sleep quality, exacerbating relationships with family and peers, and even substance use $(5,6)$.

As a non-substance addiction (7), like gambling disorder (8), Internet Gaming disorder (IGD) was enrolled in the Fifth Edition of the Diagnostic and Statistical Manual of Mental Disorders (DSM-5) in 2013, warranting further research (9). In 2018, the International Classification of Diseases (ICD-11) also considered including it as a disease (10). Due to the differences in measurement tools and cultural backgrounds, different prevalence rates of IGD were reported among young people. For example, prevalence in Europe was between 1.2 and $1.6 \%(11,12)$, while in Asia it ranged from 1.6 to $18.4 \%$ (1315). Some studies reported that the rates of possible IGD among adolescents in China ranged between 2.0 (15) and 17.0\% (16). However, more research on epidemiological investigation based on large samples should be conducted to verify those figures.

IGD is not only related to the stimulation of the game itself but also linked to the personality traits of the players. Personality traits can be considered as determinants of one's behaviors (17), which are enduring dispositions characterized by individuals' unique adaptation to others, themselves, objects, and even to the whole environment. According to the diathesisstress model of behavior, addictive disorders may result from specific personality traits $(1,17)$. Strong empirical evidence has indicated that some personality traits were linked to antisocial behaviors, violence (18), substance use (19), and gambling (20). For example, heightened extraversion may be a predictor of smoking and alcohol consumption (21). Smokers scored higher on neuroticism and lower on conscientiousness and agreeableness than non-smokers (19).

Despite some controversies (22), the Five-Factor model is the most common classification of personality characteristics (23). The Big-Five model includes five personality dimensions: extraversion (people who are sociable and talkative), agreeableness (well-mannered and soft-hearted), neuroticism (unstable and short-tempered), conscientiousness (organized and hardworking), and openness to experience (curious and original) (24). A recent meta-analysis review revealed all personality dimensions had a significant effect on Internet addiction, based on 12 different studies (25). Easygoing, outgoing, responsible, and more neurotic individuals who were less open to experience showed higher levels of Internet addiction. Furthermore, individuals showing high levels of high conscientiousness (persistence, reliability, and an orientation toward achievement) may better predict general and mental health states (26). Studies of personality and health have shown that neuroticism in particular can be a common risk factor for poor health (27). To date, there has been limited research on the relationship between personality traits and IGD $(1,28-30)$, and these studies assessed personality traits using different assessment tools. Therefore, it is hard to compare or synthesize the results of their findings. Most research suggested a positive correlation between neuroticism and IGD; however, results for other personality traits have been inconsistent.

To better understand the risk factors of IGD, it is equally crucial to comprehend the association between IGD and Internet gaming use characteristics. Some researchers demonstrated that Internet gaming characteristics were significantly correlated with IGD. For example, Rho et al. (29) found that many significant behavioral factors can predict IGD, such as weekday game time, money spent on gaming, game club membership status, and offline game club attendance. Middle school students who played games more than $3 \mathrm{~h}$ a day were identified as having higher degrees of gaming addiction than others (30). Over $75 \%$ of gamers played with guild members; compared to playing solo, playing with others may be more stimulating (28).

This study is the first to investigate the association of IGD with the Big-Five factors and Internet gaming characteristics in a large sample of Chinese adolescent game players. It provides empirical evidence for understanding the etiology of IGD.

\section{MATERIALS AND METHODS}

\section{Subjects}

We conducted our study as an online survey in China in October and November 2019 via WeChat (a social app used by more than one billion people) based on the survey program Questionnaire Star (a free online questionnaire survey evaluation and voting platform). People could browse the questionaire page by scanning the quick response $(\mathrm{QR})$ code. In the first page, 
there was a brief introduction on the aim of this investigation, and its voluntary, anonymity and confidentiality, as well as the notes for filling in the questions. At the bottom of this page, persons could choose "reject" to refuse participating this survey, or "accept" to switch to the next page and continue filling the queastionaire. Anyone with access to the Internet who understand Chinese could participate. As an incentive for completing the questionnaire, participants could receive feedback on their results, including personality characteristics, and suggestions for their gaming behavior.

Online participants comprised adolescents and young adults, aged 15-25 years, from 34 provincial administrative districts in China. Among 8,592 respondents, 6,379 Internet game users were identified. Those who never played Internet games $(n=1403)$ or had severe physical or mental disorders $(n=462)$ were excluded. Additionally, we removed exaggerated responses (e.g., selected the same option for all items, $n=319)$ and multiple responses from the same IP addresses $(n=29)$.

The Institutional Review Board of Second Xiangya Hospital of Central South University approved this study protocol. All subjects were fully informed about the purpose of this investigation and signed online informed consent.

\section{Procedures and Measures}

We used self-administered composite questionnaires to obtain demographic information, gaming use characteristics, IGD, and personality traits. We conducted a preliminary study in a small sample of adolescents and finalized the questionnaire before starting the study.

Demographic information included age, gender, relationship status (dating/married vs. single), highest education, and family structure (having siblings or being an only child).

For gaming use characteristics, respondents reported the game device (mobile or computer) they most commonly used, the number of long-term game partners they had, their motives for gaming, and the amount of money (monthly) and time (daily) they spent gaming over the past 12 months.

IGD was assessed by the Chinese version of Video Gaming Dependency Scale (VGD-S), which was revised from the English version developed by Rehbein et al. (11), covering all nine criteria of the DSM-5. For each criterion, there were two items. Participants were asked to choose each of the 18 descriptive items they had experienced in the past 12 months on a fourpoint Likert scale ranging from 1 (total disagreement) to 4 (full agreement). A criterion was met if at least one of the two items was answered with 4 (full agreement). Participants who endorsed five or more of the nine criteria were classified with IGD. The VGD-S was evaluated in a sample of 11,003 German students, aged 13-18, demonstrating good reliability of Cronbach's $\alpha$ with 0.93 (11). The Chinese version of the VGD-S yielded an internal consistency of 0.94 in this research.

Personality traits were assessed by the 40 -item brief version of the Chinese Big Five Inventory (CBF-PI-B) (31-33). Bigfive personality traits were measured with eight items mapping each dimension: conscientiousness, extraversion, agreeableness, neuroticism, and openness. Responses were on a six-point Likert scale ranging from 1 (strongly disagree) to 6 (strongly agree). The CBF-PI-B demonstrates high construct validity and reliability, and the internal consistency coefficient was between 0.76 (agreeableness) and 0.81 (neuroticism), with an average of 0.79 (31). The retest coefficient of the 10 -week interval ranged from 0.67 (agreeableness) to 0.81 (openness), with an average of 0.74 (31). In this study the CBF-PI-B yielded an internal consistency of 0.86 .

\section{Statistical Analysis}

Prevalence of IGD in the whole sample was calculated. We used chi-square tests and $t$-tests to compare demographics, Internet gaming use characteristics, and personality traits between the IGD group and the non-IGD group. In univariate analysis, via a backward stepwise entry, multiple linear regression was performed to determine risk factors related to IGD. The statistical significance level was set at $p<0.001$ (two-sided). We used SPSS software version 23.0 package for all analyses.

\section{RESULTS}

In this study, a total of 6,379 adolescent game players were recruited from 34 provincial administrative districts in China. The average age of the 6,379 participants was 19.4 years [standard deviation [SD]:1.6, range:15-25], and 57.1\% were male adolescents (males/females $=3,701 / 2,678$ ). The average time spent on gaming was $1.8 \mathrm{~h}$ per day (SD:1.3) and the average amount of money spent on gaming was 63.9 yuan per month (SD:145.2). Table 1 displayed the detailed sociodemographic and Internet gaming characteristics of the participants.

According to the positive criteria, endorsement of five or more of the nine criteria, a total of 1,084 adolescents (17\%) were classified with IGD. All participants were divided into the IGD group (males/females $=751 / 333$, mean age: $19.74 \pm 1.85$ ) and non-IGD group (males/females $=2,950 / 2,345$, mean age: 19.27 $\pm 1.54)$. Results from the Chi-square tests and T-test (Table 1 ) show that IGD groups were more likely to be male $(p<0.001)$, single $(p<0.001)$, undergraduate or above $(p<0.001)$, older $(p<0.001)$, use computers to play $(p<0.001)$, have one or two long-term game players $(p<0.001)$, play games for seeking $(p<0.001)$ and escaping $(p<0.001)$, and spend more time and money on gaming $(p<0.001)$. To control the effect of socio-demographic variables, sex, education and relationship status, personality traits and Internet gaming characteristics were included in a multiple linear regression. All variables included in the linear regression model did not show multicollinearity (VIF: 1.021-2.207), and the Durbin-Watson was 1.906, so assumptions of collinearity were not violated. The association between IGD and predictive variables were strongly relative. Together, all the predictive variables accounted for $38.7 \%$ of the variance in IGD scores and the explained variability was also significant, F $(18,6378)=224.276, p<0.001$.

Multiple linear regression analysis showed that twelve factors were significantly associated with IGD, including neuroticism $(\beta=0.17, p<0.001)$, conscientiousness $(\beta=-0.14, p<0.001)$, Internet gaming time per day (Hour) $(\beta=0.21, p<0.001)$, Internet gaming charge per month (Yuan) $(\beta=0.21, p<0.001)$, motive: escaping $(\beta=0.15, p<0.001)$, motive: sensation seeking 
TABLE 1 | Socio-demographic and Internet gaming characteristics of participants and comparison between IGD group and Non-IGD group by variables.

\begin{tabular}{|c|c|c|c|c|c|c|}
\hline Variables & & $\begin{array}{c}\text { Total } \\
(\mathrm{N}=6,379)\end{array}$ & $\begin{array}{l}\text { IGD group } \\
(n=1,084)\end{array}$ & $\begin{array}{l}\text { Non-IGD group } \\
\quad(n=5,295)\end{array}$ & $\mathrm{c}^{2}$ or $\mathrm{t}$ & $p$ \\
\hline Gender & Male & 3,701 & 751 & 2,950 & 68.001 & $<0.001$ \\
\hline Age (years) & & $19.35 \pm 1.61$ & $19.74 \pm 1.85$ & $19.27 \pm 1.54$ & -8.743 & $<0.001$ \\
\hline Relationship status & Couple & 135 & 83 & 52 & 48.483 & $<0.001$ \\
\hline & Above & 3,738 & 731 & 3,007 & & \\
\hline \multirow[t]{2}{*}{ Family structure } & having siblings & 3,166 & 530 & 2,636 & 0.285 & 0.773 \\
\hline & being an only child & 3,213 & 554 & 2,659 & & \\
\hline \multicolumn{7}{|l|}{ Gaming use characteristics } \\
\hline Device & PC & 2,008 & 685 & 1,323 & 608.93 & $<0.001$ \\
\hline Long-term game partners & $N \geq 6$ & 723 & 152 & 571 & & \\
\hline Daily gaming time(hours) & & $1.83 \pm 1.30$ & $2.86 \pm 1.81$ & $1.62 \pm 1.05$ & -30.664 & $<0.001$ \\
\hline Money spent on gaming/month(yuan) & & $63.92 \pm 145.19$ & $179.35 \pm 241.44$ & $40.29 \pm 100.92$ & -30.791 & $<0.001$ \\
\hline \multicolumn{7}{|l|}{ Motives } \\
\hline \multirow[t]{2}{*}{ Seeking } & Yes & 1,915 & 589 & 1,326 & 367.529 & $<0.001$ \\
\hline & No & 4,464 & 495 & 3,969 & & \\
\hline \multirow[t]{2}{*}{ Escaping } & Yes & 694 & 345 & 349 & 590.99 & $<0.001$ \\
\hline & No & 5,685 & 739 & 4,946 & & \\
\hline \multirow[t]{2}{*}{ Coping } & Yes & 2,656 & 593 & 2,063 & 20.942 & $<0.001$ \\
\hline & No & 3,723 & 491 & 3,232 & & \\
\hline Neuroticism & & $25.68 \pm 7.93$ & $29.63 \pm 6.38$ & $24.87 \pm 7.98$ & -18.492 & $<0.001$ \\
\hline Conscientiousness & & $33.16 \pm 6.34$ & $30.52 \pm 5.40$ & $33.70 \pm 6.39$ & 15.286 & $<0.001$ \\
\hline Openness & & $33.27 \pm 6.96$ & $32.35 \pm 6.17$ & $33.45 \pm 7.10$ & 4.781 & $<0.001$ \\
\hline Agreeableness & & $35.10 \pm 6.11$ & $32.88 \pm 5.85$ & $35.56 \pm 6.06$ & 13.332 & $<0.001$ \\
\hline Extraversion & & $29.65 \pm 7.14$ & $28.58 \pm 6.57$ & $29.87 \pm 7.24$ & 5.445 & $<0.001$ \\
\hline
\end{tabular}

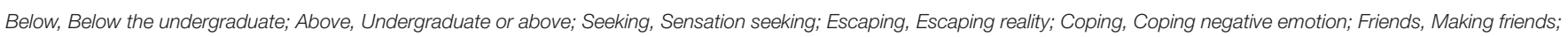
Maintaining, Maintaining status.

$(\beta=0.13, p<0.001)$, motive: Maintaining $(\beta=0.08, p<0.001)$, motive: coping $(\beta=0.06, p<0.001)$, having one or two longterm game partners $(\beta=0.06, p<0.001)$, male $(\beta=0.12$, $p<0.001)$, education of undergraduate or above $(\beta=0.04$, $p<0.001)$, and relationship status of couple $(\beta=0.04, p<0.001)$ (see Table 2).

\section{DISCUSSION}

Our study is one of few to determine the relationships between IGD, Internet gaming use characteristics, and Big-Five personality traits. This is the first investigation of the prevalence of IGD in a large sample $(>6,000)$ of adolescent game players in China. We found that nearly $17.0 \%$ of Chinese adolescent game users reported IGD, which was significantly associated with gender, highest education, relationship status, Internet gaming use characteristics (money spent per month, time spent per day, and long-term game partners), motivation (escape, sensation seeking, maintaining, and coping) and personality traits (neuroticism, conscientiousness).

In this study, we found a $17 \%$ prevalence of IGD among Chinese adolescent gaming users, the exact same percentage 
TABLE 2 | Multivariable linear regression of factors associated with IGD.

\begin{tabular}{|c|c|c|c|c|c|}
\hline & B & SE B & $\beta$ & $P$ & VIF \\
\hline Neuroticism & 0.053 & 0.003 & 0.172 & $<0.001$ & 1.206 \\
\hline Conscientiousness & -0.050 & 0.005 & -0.140 & $<0.001$ & 1.812 \\
\hline Agreeableness & 0.011 & 0.005 & 0.028 & 0.016 & 1.438 \\
\hline Openness & 0.006 & 0.005 & 0.017 & 0.237 & 2.207 \\
\hline Extraversion & -0.011 & 0.004 & -0.027 & 0.027 & 1.523 \\
\hline Device & -0.03 & 0.059 & -0.005 & 0.639 & 1.173 \\
\hline Long-term game partner & 0.329 & 0.052 & 0.062 & $<0.001$ & 1.021 \\
\hline Money spent on gaming/month & 0.003 & 0.000 & 0.206 & $<0.001$ & 1.354 \\
\hline Gaming time/day & 0.395 & 0.021 & 0.209 & $<0.001$ & 1.298 \\
\hline Sensation seeking & 0.675 & 0.056 & 0.126 & $<0.001$ & 1.141 \\
\hline Escaping & 1.179 & 0.084 & 0.149 & $<0.001$ & 1.180 \\
\hline Coping negative emotion & 0.321 & 0.051 & 0.064 & $<0.001$ & 1.075 \\
\hline Passing time & 0.026 & 0.052 & 0.005 & 0.623 & 1.042 \\
\hline Making friends & 0.062 & 0.064 & 0.010 & 0.327 & 1.039 \\
\hline Maintaining & 0.481 & 0.060 & 0.080 & $<0.001$ & 1.049 \\
\hline Gender & 0.580 & 0.054 & 0.116 & $<0.001$ & 1.217 \\
\hline Highest education & 0.191 & 0.050 & 0.038 & $<0.001$ & 1.023 \\
\hline Relationship states & 0.719 & 0.176 & 0.042 & $<0.001$ & 1.098 \\
\hline
\end{tabular}

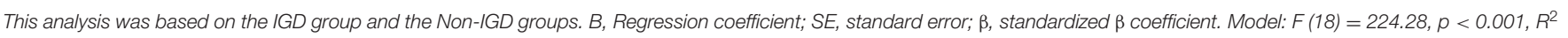
$=0.39$.

as the Experts Consensus of Gaming Disorder in China (2019 Edition) (16), which is much higher than many other countries. Using the same tools as our study, Rehbein et al. (11), the authors of the VGD-S English version, conducted a state-representative survey consisting of 11,003 middle school students and reported a $1.2 \%$ prevalence of GD. Müller et al. (12) found an IGD prevalence of $1.6 \%$ in 12,938 adolescents from seven European countries. Other studies reported significant figures: between 0.3 and $1.0 \%$ in four international groups of 18,932 people (34); $1.3 \%$ in a national sample of 902 Dutch gamers (35); and $1.8 \%$ of 1,287 Australian adolescents (36). The higher rate of IGD in this study might be related to differences in sample characteristics (based on the general population or gamers), assessments of IGD, or cultural factors. These studies, conducted in different socio-cultural populations, suggest that China's IGD prevalence is more concerning. This may be a cultural difference. Western countries have more individualistic cultures than Asian countries $(37,38)$, where higher levels of individualism were significantly associated with lower levels of Internet addiction, manifested in an increased need for achievement, dominance, and autonomy, and a reduced need for affiliation (39). Considering the negative health consequences of IGD and the vast number of Chinese adolescents, a $17 \%$ prevalence suggests that adolescent IGD in China deserves preventive and clinical attention.

Certain sociodemographic variables were more significantly associated with IGD. Consistent with previous studies (40, 41 ), we found that being male was significantly related with IGD, possibly due to gender differences in online use. To illustrate, females mostly use online networking for chatting, sharing information, tightening communication, and visiting personal websites, whereas males mostly use the Internet to play games (42). Furthermore, certain temperamental characteristics of males such as high comorbidity of Attention Deficit Hyperactivity Disorder (ADHD), high levels of novelty seeking, and high levels of impulsivity may be responsible for higher rates of IGD. Research also indicated that roughly four in five Massively Multiplayer Online Roleplaying Game (MMORPG) players were males (28). Many games on the market are invented by males for males (43); gaming companies strategically target boys and men to increase their sales $(44,45)$, partly explaining the high rate of male gaming usage.

Unlike previous studies $(29,46,47)$, we found that dating or married and highly educated young adults were more likely to have IGD. Rho et al. (29) found there was no significant differece on marital status and education between the IGD and concrol group. A clinical research showed that patients with IGD were more likely single (46). Being single was positively associated to addictive video gaming, which may be related with their loneliness (47). The opposite results in this study may due to the unbalanced relationship status (135 couple vs. 6244 single) of these participants, which influenced the outcomes. The results of $t$-test showed that the IGD group was older than the nonIGD group. It can be speculated that young adults and college students tend to have more autonomy and opportunities to use smart devices than younger students do. Therefore, due to their technological proficiency and lack of external supervision, they may be more prone to suffer from gaming disorders (14). More research is needed to verify these results.

In the current study, IGD was significantly associated with the personality traits of neuroticism and conscientiousness, which is consistent with previous reports (48-50). Our study indicated 
a significant relationship between neuroticism and IGD, which correlates to a previous finding that when highly neurotic individuals consider the real world threatening, they often turn to digital worlds, where they feel in control and safe (1). Since previous research has reported that high level of neuroticism is a predictor for smoking (51) and correlated with other mental disorders (52), it may represent a general health risk factor. Our results also suggested a significant relationship between low conscientiousness and IGD. Low conscientiousness indicates one has less commitment to personal goals, a tendency to be disorganized, and trouble organizing and following a schedule (53); therefore, the digital environment may be more attractive (1). Consequently, paying particular attention to adolescents with high neuroticism or low conscientiousness may help prevent IGD.

We found that personality traits like openness, agreeableness, and extraversion were not associated with IGD. However, several studies reported a slightly significant correlation between low openness and IGD (54), low agreeableness associated with Internet addiction (55), and IGD patients displaying lower extraversion than control groups and groups of pathological gamblers (1). For example, game players with low levels of openness are prone to stick to their gaming behavior rather than exploring new activities (1). Further studies are needed to provide more evidence.

Certain Internet gaming characteristics, like having one or two long-term game partners, significantly predicted IGD. For example, MMORPGs encourage gamers to team up with other players to progress (28), inspiring teamwork and interaction $(56,57)$. Generally, gamers with IGD were considered to be isolated and have not many social relationships in the real world, while they developed long-term relationships with their game partners, such as attending offline game clubs and having game club memberships (29).

Consistent with findings on risk factors of IGD in the general population, the motives of escaping reality, sensation seeking, and coping with negative emotions were significantly associated with IGD. Sensation seeking may provide a coping strategy for boredom (58); this is a positive reinforcement for IGD. Furthermore, the diversity of online games is a preferable alternative to dealing with negative emotions (59) that are often associated with high neuroticism. Players who enjoy role-playing games engage in gaming to relax and temporarily escape real life (60). Alternatively, coping with negative emotions such as fear of failure can be seen as negative reinforcement for IGD $(44,61,62)$. Many studies have shown that the feeling-of-escape motive is most strongly associated with and most predictive of $\operatorname{IGD}(28,44)$.

Gaming costs and daily gaming time were additional risk factors of IGD. Users with IGD spent more time (2.86 vs. $1.62 \mathrm{~h}$ per day) and more money (179.35 vs. 40.29 yuan per month) than the non-IGD group. Those scoring low in conscientiousness had difficulty controlling the amount of time and money they spent on gaming. Previous studies reported that spending large amounts of time and money was a predictor of IGD (29). Many gamers report difficulty in controlling gaming time. Rho et al. (63) also showed that money and time spent on gaming are risk factors for IGD. Zaheer Hussain found that if a player spends more time playing games online, the risk of being addicted increases (28); therefore, corresponding measures should be taken to prevent and manage IGD, such as strictly controlling gaming time and money spent.

This study had some limitations. First, using self-reported questionnaires instead of face-to-face structured interviews requires that more caution is taken when generalizing the findings. However, self-reported investigations completed online are thought to improve honesty levels (64). Second, this study was a cross-sectional survey, so findings regarding relationships may not be causal. However, personality traits are relatively stable in life, so interpreting differences in personality traits is reasonable (1). Third, we used short versions of the Big-Five scale; although the complete versions may be more reliable and detailed, the short version appears to be psychometrical and more helpful for a large-scale survey. Fourth, the sociodemographic characteristics of the non-IGD group did not exactly match those of the IGD group, possibly leading to confounding results.

\section{CONCLUSIONS}

This study found significant associations between IGD and personality factors, Internet gaming characteristics in China. Given that China appears to have a higher IGD prevalence rate than other regions, it is necessary for Chinese parents, teachers, and social workers to pay more attention to the mental needs of adolescents in terms of personality traits and gaming use. A three-level prevention system is worth adopting to assist with general prevention, targeted prevention, and early detection and treatment (16). Future research should be conducted to explore how these factors influence IGD and examine the development of IGD.

\section{DATA AVAILABILITY STATEMENT}

All relevant data is contained within the article: The original contributions presented in the study are included in the article/supplementary material, further inquiries can be directed to the corresponding author/s.

\section{ETHICS STATEMENT}

The studies involving human participants were reviewed and approved by The Institutional Review Board of Second Xiangya Hospital of Central South University. The patients/participants provided their written informed consent to participate in this study.

\section{AUTHOR CONTRIBUTIONS}

All authors made substantial contributions to this study. ZL, QH, and HS conceptualized and designed the research, wrote the first draft of the manuscript, and contributed to the final manuscript. TS, TF, and XC prepared the assessment tools. LT, SL, and JQ performed the experiments. $\mathrm{SH}$ and $\mathrm{YC}$ undertook the statistical 
analysis. All authors critically reviewed content and approved final version for publication.

\section{FUNDING}

This work was supported by National Natural Science Foundation of China (81971249), National Basic Research

\section{REFERENCES}

1. Müller KW, Beutel M, Egloff B, Wölfling K. Investigating risk factors for Internet gaming disorder: a comparison of patients with addictive gaming, pathological gamblers and healthy controls regarding the big five personality traits. Eur Addict Res. (2014) 20:129-36. doi: 10.1159/000355832

2. Cnnic. The 44th China Statistical Report on Internet Development. Beijing (2019). p. 23.

3. Wilms IL, Petersen A, Vangkilde S. Intensive video gaming improves encoding speed to visual short-term memory in young male adults. Acta Psychol. (2013) 142:108-18. doi: 10.1016/j.actpsy.2012.11.003

4. Young KS. Internet addiction: the emergence of a new clinical disorder. Cyberpsychol Behav. (1998) 1:237-44. doi: 10.1089/cpb.1998.1.237

5. Greydanus DE, Greydanus MM. Internet use, misuse, and addiction in adolescents: current issues and challenges. Int J Adolesc Med Health. (2012) 24:283-9. doi: 10.1515/ijamh.2012.041

6. Huang Q, Li Y, Huang S, Qi J, Shao T, Chen X, et al. Smartphone use and sleep quality in Chinese college students: a preliminary study. Front Psychiatry. (2020) 11:352. doi: 10.3389/fpsyt.2020.00352

7. Association AP. Diagnostic and Statistical Manual of Mental Disorders (DSM-5®) American Psychiatric Pub, Arlington, VA: American Psychiatric Association Publishing (2013).

8. Mann K, Fauth-Buhler M, Higuchi S, Potenza MN, Saunders JB. Pathological gambling: a behavioral addiction. World Psychiatry. (2016) 15:297-8. doi: 10.1002/wps.20373

9. Petry NM, Rehbein F, Gentile DA, Lemmens JS, Rumpf HJ, Mossle T, et al. An international consensus for assessing internet gaming disorder using the new DSM-5 approach. Addiction. (2014) 109:1399-406. doi: 10.1111/add.12457

10. World Health Organization. WHO Releases New International Classification of Diseases (ICD 11) (2018). Available online at: https://www.who.int/ news/item/18-06-2018-who-releases-new-international-classification-ofdiseases-(icd-11)

11. Rehbein F, Kliem S, Baier D, Mößle T, Petry NM. Prevalence of internet gaming disorder in German adolescents: diagnostic contribution of the nine DSM-5 criteria in a state-wide representative sample. Addiction. (2015) 110:842-51. doi: 10.1111/add.12849

12. Müller KW, Janikian M, Dreier M, Wölfling K, Beutel M, Tzavara C, et al. Regular gaming behavior and internet gaming disorder in European adolescents: results from a cross-national representative survey of prevalence, predictors, and psychopathological correlates. Eur Child Adolesc Psychiatry. (2015) 24:565-74. doi: 10.1007/s00787-014-0611-2

13. King DL, Chamberlain SR, Carragher N, Billieux J, Stein D, Mueller $\mathrm{K}$, et al. Screening and assessment tools for gaming disorder: a comprehensive systematic review. Clin Psychol Rev. (2020) 77:101831. doi: 10.1016/j.cpr.2020.101831

14. Chia DXY, Ng CWL, Kandasami G, Seow MYL, Choo CC, Chew $\mathrm{PKH}$, et al. Prevalence of internet addiction and gaming disorders in Southeast Asia: a meta-analysis. Int J Environ Res Public Health. (2020) 17:2582. doi: 10.3390/ijerph17072582

15. Mak KK, Lai CM, Watanabe H, Kim DI, Bahar N, Ramos M, et al. Epidemiology of internet behaviors and addiction among adolescents in six Asian countries. Cyberpsychol Behav Soc Netw. (2014) 17:7208. doi: 10.1089/cyber.2014.0139

16. Xiang YT, Jin $\mathrm{Y}$, Zhang $\mathrm{L}$, Li L, Ungvari GS, $\mathrm{Ng} \mathrm{CH}$, et al. An overview of the expert consensus on the prevention and treatment of gaming disorder in China (2019 Edition). Neurosci Bull. (2020) 36:8258. doi: $10.1007 / \mathrm{s} 12264-020-00475-\mathrm{w}$
Program of China (2015CB553504), and National Research Program of China (2016YFC0800908-Z02).

\section{ACKNOWLEDGMENTS}

The authors would like to thank all the participants.
17. Mccrae RR, Costa PT Jr. Personality trait structure as a human universal. Am Psychol. (1997) 52:509. doi: 10.1037/0003-066X.52.5.509

18. Yu R, Geddes JR, Fazel S. Personality disorders, violence, and antisocial behavior: a systematic review and meta-regression analysis. J Pers Disord. (2012) 26:775-92. doi: 10.1521/pedi.2012.26.5.775

19. Terracciano A, Costa PT Jr. Smoking and the five-factor model of personality. Addiction. (2004) 99:472-81. doi: 10.1111/j.1360-0443.2004.00687.x

20. Miller JD, Mackillop J, Fortune EE, Maples J, Lance CE, Campbell WK, et al. Personality correlates of pathological gambling derived from big three and big five personalitymodels. Psychiatry Res. (2013) 206:505. doi: 10.1016/j.psychres.2012.09.042

21. Paunonen SV. Big five factors of personality and replicated predictions of behavior. J Pers Soc Psychol. (2003) 84:41124. doi: 10.1037/0022-3514.84.2.411

22. Block J. A contrarian view of the five-factor approach to personality description. Psychol Bull. (1995) 117:187215. doi: 10.1037/0033-2909.117.2.187

23. Mccrae RR. 5 Years of Progress: A Reply to Block. Elsevier (2001) 35:10813. doi: $10.1006 /$ jrpe.2000.2294

24. Mccrae RR, John OP. An introduction to the fivefactor model and its applications. J Pers. (1992) 60:175215. doi: 10.1111/j.1467-6494.1992.tb00970.x

25. Kayiş AR, Satici SA, Yilmaz MF, Simşek D, Ceyhan E, Bakioglu F. Big fivepersonality trait and internet addiction: a meta-analytic review. Comput Hum Behav. (2016) 63:35-40. doi: 10.1016/j.chb.2016.05.012

26. Christensen AJ, Ehlers SL, Wiebe JS, Moran PJ, Raichle K, Ferneyhough $\mathrm{K}$, et al. Patient personality and mortality: a 4-year prospective examination of chronic renal insufficiency. Health Psychol. (2002) 21:315-20. doi: 10.1037//0278-6133.21.4.315

27. Brickman AL, Yount SE, Blaney NT, Rothberg ST, De-Nour AK. Personality traits and long-term health status. The influence of neuroticism and conscientiousness on renal deterioration in type-1 diabetes. Psychosomatics. (1996) 37:459-68. doi: 10.1016/S0033-3182(96)71534-7

28. Hussain Z, Griffiths MD, Baguley T. Online gaming addiction: classification, prediction and associated risk factors. Addict Res Theory. (2012) 20:35971. doi: 10.3109/16066359.2011.640442

29. Rho MJ, Lee H, Lee TH, Cho H, Jung DJ, Kim DJ, et al. Risk factors for internet gaming disorder: psychological factors and internet gaming characteristics. Int J Environ Res Public Health. (2018) 15:40. doi: 10.3390/ijerph15 010040

30. Karaca S, Karakoc A, Can Gurkan O, Onan N, Unsal Barlas G. Investigation of the online game addiction level, sociodemographic characteristics and social anxiety as risk factors for online game addiction in middle school students. Commun Ment Health J. (2020) 56:830-8. doi: 10.1007/s10597-019-0 0544-z

31. Wang MC, Dai XY, Yao SQ. Development of the Chinese big five personality inventory (CBF-PI) III: psychometric properties of CBF-PI brief version. Chin J Clin Psychol. (2011) 19:454-7. doi: 10.16128/j.cnki.1005-3611.2011.04.004

32. Wang MC, Dai XY, Yao SQ. Development of the Chinese big five personality inventory (CBF-PI) II: validity analysis. Chin J Clin Psychol. (2010) 18:687-90. doi: 10.16128/j.cnki.1005-3611.2015.04.001

33. Wang MC, Dai XY, Yao SQ. Development of Chinese big five personality inventory(CBF-PI): theoretical framework and relability analysis. Chin J Clin Psychol. (2010) 18:545-8. doi: 10.16128/j.cnki.1005-3611.2015.03.001

34. Przybylski AK, Weinstein $\mathrm{N}$, Murayama K. Internet gaming disorder: investigating the clinical relevance of a new phenomenon. Am J Psychiatry. (2017) 174:230-6. doi: 10.1176/appi.ajp.2016.16020224 
35. Haagsma MC, Pieterse ME, Peters O. The prevalence of problematic video gamers in the Netherlands. Cyberpsychol Behav Soc Netw. (2012) 15:1628. doi: 10.1089/cyber.2011.0248

36. King DL, Delfabbro PH, Zwaans T, Kaptsis D. Clinical features and axis I comorbidity of Australian adolescent pathological Internet and video game users. Aust $N$ Z J Psychiatry. (2013) 47:1058-67. doi: 10.1177/0004867413491159

37. Oyserman D, Lee SW. Does culture influence what and how we think? Effects of priming individualism and collectivism. Psychol Bull. (2008) 134:311. doi: 10.1037/0033-2909.134.2.311

38. Oyserman D, Coon HM, Kemmelmeier M. Rethinking individualism and collectivism: evaluation of theoretical assumptions and meta-analyses. Psychol Bull. (2002) 128:3-72. doi: 10.1037/0033-2909.128.1.3

39. Arpaci I, Kesici S, Baloglu M. Individualism and internet addiction: the mediating role of psychological needs. Int Res. (2018) 28:293314. doi: 10.1108/IntR-11-2016-0353

40. Hyun GJ, Han DH, Lee YS, Kang KD, Yoo SK, Chung US, et al. Risk factors associated with online game addiction:a hierarchical model. Comput Hum Behav. (2015) 48:706-13. doi: 10.1016/j.chb.2015.02.008

41. Yang DJ, Chiu JZ, Chen YK. Examining the social influence on college students for playing online game: gender differences and implications. Turkish Online J Educ Technol. (2011) 10:115-22.

42. Gross EF. Adolescent Internet use: what we expect, what teens report. J Appl Dev Psychol. (2004) 25:633-49. doi: 10.1016/j.appdev.2004.09.005

43. Spekman ML, Konijn EA, Roelofsma PH, Griffiths MD. Gaming addiction, definition and measurement: a large-scale empirical study. Comput Hum Behav. (2013) 29:2150-5. doi: 10.1016/j.chb.2013.05.015

44. Kuss DJ. Internet gaming addiction: current perspectives. Psychol Res Behav Manag. (2013) 6:125-37. doi: 10.2147/PRBM.S39476

45. Vollmer C, Randler C, Horzum MB, Ayas T. Computer game addiction in adolescents and its relationship to chronotype and personality. Sage Open. (2014) 4:2158244013518054. doi: 10.1177/2158244013518054

46. Mallorquí-Bagué N, Fernández-Aranda F, Lozano-Madrid M, Granero R, Mestre-Bach G, Baño M, et al. Internet gaming disorder and online gambling disorder: clinical and personality correlates. J Behav Addict. (2017) 6:66977. doi: $10.1556 / 2006.6 .2017 .078$

47. Schou Andreassen C, Billieux J, Griffiths MD, Kuss DJ, Demetrovics Z, Mazzoni E, et al. The relationship between addictive use of social media and video games and symptoms of psychiatric disorders: a large-scale cross-sectional study. Psychol Addict Behav. (2016) 30:25262. doi: $10.1037 /$ adb0000160

48. Van Der Aa N, Overbeek G, Engels RC, Scholte RH, Meerkerk G-J, Van Den Eijnden RJ. Daily and compulsive internet use and well-being in adolescence: a diathesis-stress model based on big five personality traits. J Youth Adolesc. (2009) 38:765. doi: 10.1007/s10964-008-9298-3

49. Yan W, Li Y, Sui N. The relationship between recent stressful life events, personality traits, perceived family functioning and internet addiction among college students. Stress Health. (2014) 30:3-11. doi: 10.1002/smi.2490

50. Yao MZ, He J, Ko DM, Pang K. The influence of personality, parental behaviors, and self-esteem on Internet addiction: a study of Chinese college students. Cyberpsychol Behav Soc Netw. (2014) 17:104-10. doi: 10.1089/cyber.2012.0710
51. Soldz S, Vaillant GE. The big five personality traits and the life course: a 45-year longitudinal study. J Res Pers. (1999) 33:208-32. doi: 10.1006/jrpe.1999.2243

52. Kotov R, Gamez W, Schmidt F, Watson D. Linking "big” personality traits to anxiety, depressive, and substance use disorders: a meta-analysis. Psychol Bull. (2010) 136:768. doi: 10.1037/a0020327

53. Ross C, Orr ES, Sisic M, Arseneault JM, Simmering MG, Orr RR. Personality and motivations associated with facebook use. Comput Hum Behav. (2009) 25:578-86. doi: 10.1016/j.chb.2008.12.024

54. Wang CW, Ho RT, Chan CL, Tse S. Exploring personality characteristics of Chinese adolescents with internet-related addictive behaviors: trait differences for gaming addiction and social networking addiction. Addict Behav. (2015) 42:32-5. doi: 10.1016/j.addbeh.2014.10.039

55. Kuss DJ, Griffiths MD, Binder JF. Internet addiction in students: prevalence and risk factors. Comput Hum Behav. (2013) 29:95966. doi: 10.1016/j.chb.2012.12.024

56. Griffiths M. A 'components' model of addiction within a biopsychosocial framework. J Subst Use. (2005) 10:191-7. doi: 10.1080/14659890500114359

57. Hussain Z, Griffiths MD. Gender swapping and socializing in cyberspace: an exploratory study. Cyberpsychol Behav. (2008) 11:47-53. doi: 10.1089/cpb.2007.0020

58. Chiu S-I Lee JZ, Huang DH. Video game addiction in children and teenagers in Taiwan. CyberPsychol Behav. (2004) 7:571-81. doi: 10.1089/cpb.2004.7.571

59. Hinojosa JA, Méndez-Bértolo C, Pozo MA. Looking at emotional words is not the same as reading emotional words: behavioral and neural correlates. Psychophysiology. (2010) 47:748-57. doi: 10.1111/j.1469-8986.2010.0 0982.x

60. Yee N. Motivations for play in online games. Cyber Psychol Behav. (2006) 9:772-5. doi: 10.1089/cpb.2006.9.772

61. Bass PF III. Gaming addiction when going online goes off-kilter. Contemp Pediatr. (2015) 32:16.

62. Columb D, Griffiths MD, O'gara C. Online gaming and gaming disorder: more than just a trivial pursuit. Ir J Psychol Med. (2019) 1-7. doi: 10.1017/ipm.2019.31

63. Rho MJ, Jeong JE, Chun JW, Cho H, Jung DJ, Choi IY, et al. Predictors and patterns of problematic Internet game use using a decision tree model. J Behav Addict. (2016) 5:500-9. doi: 10.1556/2006.5.2016.051

64. Wood RT, Griffiths MD, Eatough V. Online data collection from video game players: methodological issues. Cyberpsychol Behav. (2004) 7:5118. doi: 10.1089/cpb.2004.7.511

Conflict of Interest: The authors declare that the research was conducted in the absence of any commercial or financial relationships that could be construed as a potential conflict of interest.

Copyright (c) 2020 Liao, Huang, Huang, Tan, Shao, Fang, Chen, Lin, Qi, Cai and Shen. This is an open-access article distributed under the terms of the Creative Commons Attribution License (CC BY). The use, distribution or reproduction in other forums is permitted, provided the original author(s) and the copyright owner(s) are credited and that the original publication in this journal is cited, in accordance with accepted academic practice. No use, distribution or reproduction is permitted which does not comply with these terms. 